\title{
Clinical formulation: where it came from, what it is and why it matters
}

\author{
John Baird, Alan Hyslop, Marjorie Macfie, Ruth Stocks \& Tessa Van der Kleij
}

\begin{abstract}
SUMMARY
Clinical formulation was introduced in its present form a little over 30 years ago and is, in essence, a concise summary of the origins and nature of a person's problems, together with opinion on what may go wrong in the future and what steps should be taken to improve matters. In our article we discuss how, in recent times, the task of preparing a clinical formulation has rightly become a multidisciplinary exercise involving the whole clinical team and, even more important, that nowadays the patient - the subject of the clinical formulation - together with their carers should also be actively involved in the process and feel some ownership of the conclusions and decisions. In addition, we compare these developments in clinical formulation with similar developments, arising for the same reasons, in clinical teaching and education.
\end{abstract}

\section{LEARNING OBJECTIVES}

- Understand the core principles of formulation

- Know how to prepare a formulation within a clinical team

- Understand the role that formulation plays in the effective management of patients

\section{DECLARATION OF INTEREST}

None

Formulation has an important place in modern clinical practice, but the term only came into regular use in relatively recent times. The Companion to Psychiatric Studies (Forrest 1973) does not have the word in the index, but Clinical Psychiatry (Slater 1977: p. 35) does, and there it is defined as:

'A detailed statement of the diagnosis in multidimensional terms. It will contain a classification of the disorder and a specification of the factors, physical, constitutional and psychogenic, which have contributed to its appearance. It will also contain a short plan for further investigation and treatment'.

The definition concludes:

'It is a more difficult matter than the description of past and present in extended form and will test all the psychiatrist's powers of judgement and wealth of experience.'
Although written only 40 years ago, this last sentence in particular sounds to be from a very different age. The Concise Oxford Textbook of Psychiatry (Gelder 1994) describes the process in similar terms and defines a formulation as:

'concise assessments of diagnosis, aetiology, treatment and prognosis [...] it is not merely a summary in another form but an exercise in clinical reasoning'.

In this article we discuss how the concept of formulation has evolved since those times. In particular, explicit multidisciplinary contributions to the preparation of a formulation have become expected and, even more recently, it has been realised that patients themselves, the subjects of the formulation, should be actively involved through being able to question and contribute, should they wish to do so. The therapeutic benefits of this active participation cannot be overestimated. Indeed, it is expected under the terms of current General Medical Council (2013) guidelines on good medical practice and is required following the recent judgment by the UK Supreme Court in Montgomery $v$ Lanarkshire Health Board [2015], the implications of which are discussed by Badenoch (2016).

\section{The Montgomery judgment}

The case that led to the Montgomery judgment concerned a young woman who was allowed to go into labour despite risks that vaginal delivery would be harmful to the baby. ${ }^{\dagger}$ These were not discussed with the woman in advance and in the event vaginal delivery became very problematic and the infant suffered serious and irreversible birth trauma. The basis of the appeal was that the woman believed that the risks and the options should have been discussed fully with her so that she could make an informed decision, and the judgment was entirely in her favour. The Court reached the conclusion that it was the patient's right in law to decide for herself what should happen. To allow the doctor to decide on the patient's behalf was not considered to be acceptable in today's society. The doctor's responsibility was to provide the patient with sufficient information to make the decision. In this case, the woman would have chosen an elective
John A. Baird is a retired consultant forensic psychiatrist, formerly in the Directorate of Forensic Mental Health in Glasgow and at the State Hospital, Carstairs. $\mathrm{He}$ is accredited by the Risk Management Authority as a risk assessor and is a member of the Parole Board of England and Wales and the Mental Health Tribunal for Scotland. Alan Hyslop was Head of eHealth with the Scottish Government until his retirement. Since retirement he has continued to work part time in eHealth with the Scottish Government. Marjorie Macfie is a consultant in the psychiatry of learning disability with NHS Greater Glasgow and Clyde. Ruth Stocks is a chartered clinical and chartered forensic psychologist specialising in the assessment and treatment of mentally disordered offenders and is professional lead for psychology in forensic mental health with the Directorate of Forensic Mental Health, NHS Greater Glasgow and Clyde. She is also a part-time Mental Welfare Commission visitor. Tessa Van der Kleij is a psychiatric registrar in the Adult Acute Mental Health Unit, Auckland City Hospital, New Zealand.

Correspondence Dr John A. Baird, Leverndale Hospital, 510 Crookston Road, Glasgow G53 7TU, UK. Email: kay.mooney@nhs.net

Copyright and usage (C) The Royal College of Psychiatrists 2017

${ }^{\dagger}$ The Montgomery case is discussed in more detail in Rix K. J. B. (2017) After a prolonged gestation and difficult labour, informed consent is safely delivered into English and Scots law. BJPsych Advances, 23: 63-72. Ed. 
caesarean section, which would almost certainly have avoided all the problems. The implications for patient participation in formulation are clear. Their participation must be active and meaningful to the level of their abilities, and most certainly not merely tokenistic. Just because a patient's problem is mental health related, or even forensic in nature, does not change the obligation to at least make every effort to confer with them and promote their understanding.

\section{The place of formulation in current practice}

Clinical formulation is widely accepted as a core component of clinical education in psychiatric training in the UK and, indeed, across the world (Royal College of Psychiatrists 2010, 2013; Royal Australian and New Zealand College of Psychiatrists 2014). The skills required to construct a formulation include the ability to integrate the synthesis of the data and highlight the relevant predisposing, precipitating, perpetuating and protective factors (Royal College of Psychiatrists 2013).

Early surveys reported a lack of consensus among psychiatrists about what should be included in clinical formulation (Hollyman 1983a,b). A more recent study examining how psychiatrists understand and use formulation found its utilisation to be dependent on both psychiatric training and clinical practice (Mohtashemi 2016). Participants reported multiple barriers to constructing formulations, such as limitations of resources, insufficient time available and pressures to use a more 'medical' model. Some felt that a professional rivalry between psychologists and psychiatrists, or between the psychological and the medical model, was a barrier to collaborative formulation, and most professed this rivalry to be unhelpful. Our view is that, although the preparation of a clinical formulation is most certainly not the sole responsibility of the team psychologist, formulation does require psychological knowledge and familiarity with psychological interventions, all of which can, in certain team settings, present difficulty. This, together with practical pressures of time and availability, is undoubtedly an everpresent obstacle to formulation in busy services.

The preparation of an entirely satisfactory clinical formulation need not be an onerous and time-consuming process and the more that professionals are exposed to the benefits of team formulation, the more likely they are to integrate it into their everyday practice. It is perhaps the lingering perception that formulation is difficult, labour intensive and 'specialist' that is the bigger obstacle to its wider use.

\section{BOX 1 Formulation in the MRCPsych Exami- nations: specialist core training}

'Intended learning outcome 2: Demonstrate the ability to construct formulations of patients' problems that include appropriate differential diagnoses

By the end of CT1 the trainee should demonstrate the ability to construct a formulation on an adult patient who has any of the common psychiatric disorders, including affective disorders; anxiety disorders; psychotic disorders; and personality disorders

By the end of $\mathrm{CT} 2$, the trainee should demonstrate the ability to independently construct a formulation on adult patients who present with a full range of psychiatric disorders including disorders of cognitive impairment; substance misuse disorders; and organic disorders

By the end of CT3, the trainee should demonstrate the ability to construct a formulation of patients with psychiatric disorders who have a learning disability or are children' (p. 116)

'Skills: Integrate information from multiple sources to formulate the case into which relevant predisposing, precipitating, perpetuating and protective factors are highlighted' (p. 45)

(Royal College of Psychiatrists 2013)

The curricula for the Royal College of Psychiatrists' MRCPsych Examinations include clinical formulation (Boxes $1 \& 2$ ), and formulation is a formal requirement in the Royal Australian and New Zealand College of Psychiatrists' (2014)

BOX 2 Formulation in the MRCPsych Examinations: specialist (higher) training

'Intended learning outcome 2: Demonstrate the ability to construct formulations of patients' problems that include appropriate differential diagnoses, liaising with other specialists and making appropriate referrals' (p. 23)

'By the end of ST4 the trainee will be able to independently construct a formulation for a patient presenting to a general working age adult in-patient and out patient service with a complex problem

By the end of ST5 the trainee will be able to independently construct a formulation for a patient presenting to one of the specialist working age adult services

By the end of ST6 the trainee will be able to supervise a Foundation Programme Trainee or a Core Psychiatry Trainee constructing a formulation of a problem experienced by a patient presenting to the working age adult service' (p. 75)

(Royal College of Psychiatrists 2010) 
clinical examinations. The Royal College of Psychiatrists (2017) has recently published good practice guidance for psychiatrists on the use of formulation in general psychiatric care.

\section{The process of formulation}

A formulation should be recorded in the letter to the referring clinician and in the admission history or case review note.

\section{Content}

The formulation should cover the following subjects (Box 3).

\section{The presenting problem}

There should be a brief restatement of the clinical problem and the questions to be answered, and a summary of the concerns that are at the core of the referral, assessment or review.

\section{The history}

Next comes a summary of what is known, and what remains unknown, about the patient's background with mention, in chronological order, of key events throughout their life to the present. This is not merely a narrative account of events, but a summary of what is considered to be significant and relevant to the current circumstances and concerns. It is helpful to think of factors that predispose to, precipitate and perpetuate the patient's difficulties, as well as strengths or protective factors that exist. There are always gaps, however, and no story is ever complete. Significant gaps should be highlighted. The benefit of these stages is that it allows a reader to understand the basis of the opinions that follow.

\section{The concerns}

There should be a summary of what may go wrong - what form any further crises are likely to take. The concerns listed should be plausible, not merely possible. The emphasis should be on the most likely rather than the most serious and should draw on the literature about outcomes relevant to the clinical problem, such as rates of relapse.

\section{The plan}

There should be a clear statement of what action is proposed and what the next steps will be. The responses to the questions and concerns must be sensible, patient centred and proportionate.

\section{Collaboration}

Collaboration is essential. First, and before writing the formulation, wherever possible the person who
BOX 3 The basic content of the formulation

Clinical formulations should set out:

- the presenting problem

- the history, including factors that: predispose to, precipitate and perpetuate and protect

- the concerns - what could go wrong

- the plan

has responsibility for its preparation should discuss it with the clinical team. Differing views are very important and must be examined. All views have some validity. Solo clinicians who are not part of a team must be mindful of the significant limitation under which they work and the associated potential for oversimplification, distortion and bias. Second, the formulation should be discussed with the patient, their views sought and their participation encouraged. They must have some feeling of ownership of the opinions and decisions.

\section{Guiding principles}

Much has been written about the underlying principles and methods of clinical formulation (e.g. Tarrier 2002; Persons 2008). Eells \& Lombart (2011) discuss in some detail the reasons why clinicians should include clinical formulation in their practice.

We consider that there are six principles that should govern the preparation of any formulation (Box 4), and the quality of a formulation can be assessed by considering the completed narrative against these standards. Formulations should be:

- chronological: the story should be mostly in the sequence in which it occurred

- concise: the prose should be clear and accessible, without professional or intra-professional jargon, cliché, unnecessary detail and repetition

- complete: whatever the questions are, they should be addressed and if there is insufficient information or understanding to allow them to

BOX 4 Six principles of formulation

Clinical formulations should be:

- chronological

- concise

- complete

- practical

- compassionate

- collaborative 
be answered then this needs to be stated, with an account of what still needs to be done

- practical: common sense should never be lost

- compassionate: compassion should be at the heart of the process, with the explanation for the presenting problem and related difficulties resting on the belief that people are products of their life experiences and, particularly, how they have been treated in childhood; whatever the circumstances may be, the views of the patient, and in some cases their carers, should contribute to the final opinions

- collaborative: the multidisciplinary team, the patient and, where possible, family and carers should all be involved.

We derived these principles from our work in forensic mental healthcare, where risk formulation is part of violence risk assessment and management and has taken on particular importance as part of the scrutiny of management decisions in forensic cases by external bodies such as courts and tribunals, but they are equally relevant in all areas of modern mental health practice.

\section{Case vignettes}

Each of the three fictitious cases below requires a different type of formulation, but with shared principles.

\section{Case one: a presentation at $A \& E$}

\section{Summary}

A 30-year-old man presented at the accident and emergency department (A\&E) of a general hospital. The presenting complaint was self-harm and suicidal thoughts. The man was originally from Croatia and he had been working on a cargo ship as a cook. It was expected of him that he would work for 6 months without a day off and at the time of his attendance he had been working continuously for the previous 5 months. He had little English, but was accompanied by another crew member who spoke reasonable English and acted as an interpreter. The ship had been offshore when the man had been observed to be expressing suicidal thoughts and had attempted to jump overboard into the sea. He had been restrained by a colleague, who got close enough to stop him, and he had been locked in his cabin for his safety. Some hours later he was found in his cabin to be attempting to harm himself by swallowing objects. He had been ingesting or attempting to ingest various materials, such as toothpaste, deodorant, soap, stuffing from a pillow and parts of a broken pen. Through the interpreter he stated that he was behaving in this way because he wanted to choke himself. He spoke of having been depressed for the previous 2 months and being constantly tired but unable to sleep, and he felt that there was no one, including his colleagues, to whom he could speak. He described the difficult circumstances and harsh environment in which he felt unable to talk about his problems.
The colleague's view was that the working conditions on the ship were normal, as far as he was concerned, and that all the workers knew what to expect. What the colleague most wanted to know was whether the man would be fit to go back to work as the ship would be leaving port again within 12 hours, with or without the man. He himself would be leaving on the ship and he added that he would like to leave even sooner.

Systematic enquiry for background information did not reveal anything of note. The man appeared to have no history of psychiatric illness and no problems with substance misuse. He appeared to have a good relationship with his parents and family in Croatia. He had a wife who worked as a cleaner, and they had no children. Physically he seemed healthy, although underweight, and there were also signs that he had been neglecting his selfcare. He was restless, at times tearful and seemed mistrustful, suspicious and irritable, but he did appear to be receptive to the suggestion that he would benefit from further psychiatric assessment.

\section{Formulation}

The central question is what should be done, and there is a great deal that is not known about the man and his background.

Nothing has emerged that suggests any predisposing problems in the man's early life or his experiences and influences as he was growing up, but enquiries into these areas were through an interpreter whose overriding concern appeared not to be the man's welfare, but the need to get the ship back to sea. It does appear that the man is suffering from a depressive episode, which could well have been precipitated by his isolation and his bleak unremitting routine. These conditions are likely to perpetuate his difficulties for as long as they continue, and there appears to be nothing within his routine on the ship that is protective for him apart from the physical restraint, confinement in his room and periodic observation of his behaviour. The need to admit him to hospital for further assessment is judged to be overwhelming and the fact that he is receptive to this proposal further raises concerns about his life and his circumstances on the ship.

Other important matters arising from the case are his immigration status and the precise details of his employment. It is important to establish what his status is on the ship and to clarify whether he is free to leave if he chooses to do so. Further enquiries will be made after he is admitted, but it will be important to obtain from the accompanying interpreter whatever factual information can be taken from him regarding the vessel, its owners and his employers. What this informant reports will be compared with the patient's subsequent statements through an independent interpreter. The concerns are for the man's welfare if he were to return to work or, at this point, if he were to be released to the community with no contacts or means of support.

The plan was to admit him to hospital and to make further enquiries into his situation, and this was discussed with him with the assistance of an interpreter who was hired from an independent interpreting service.

Finally, those involved with his case will keep in their minds the possibility that he is a victim of criminal activity, that he may be suffering 
coercion or control, or have been a victim of human traffickers.

Prepared by Dr A.B., ST2 in psychiatry, during discussion at the ward round on 1 January 2016 and discussion with the staff in A\&E who first met with the man.

\section{Key aspects of the clinical formulation of this case}

- The clinicians have questions in their minds throughout, they explore their hunches and identify and record what remains unknown.

- The formulation as written includes diagnostic, cultural and criminal justice formulation.

- Alongside speculation about the various aspects of the case, the next stage of management and the practical decisions to be taken are the clear priority.

\section{What does the formulation add?}

This patient is in a general hospital and he is likely to be assessed and managed by a number of different clinicians as he transfers between teams and services. The discipline of formulation ensures that the wider cultural complexities of the case are clearly recorded and are known from the outset by any new clinicians who become involved. It also ensures that efforts are regularly made to understand the patient's perspective. Details of the formulation will need to be updated as new information emerges, but the existing basic structure will reduce the risk that important aspects, albeit peripheral to the core psychiatric problems, are not forgotten.

\section{Case two: a mental health review in a secure hospital}

\section{Summary}

This case concerns a man, now aged 32 , who is a patient in a secure hospital. He has been there for 4 years and is the subject of a review. Decisions have to be made about the next stage of his management.

He was convicted of the culpable homicide of his wife, whom he had stabbed to death. They had been married for 6 years but had no children. He had been 27 at the time of the offence and he had never previously been charged with any form of violence. Assessment at the time of the offence concluded that he was suffering from a relapse of schizoaffective disorder.

He had been an only child brought up by grandparents after being removed from his mother's care when he was aged 4 and from that point his mother played little part in his life. He never knew his father. His school years were uneventful and after leaving he pursued a career in electronics and computing, and continued in this work until shortly before the offence.

His only significant intimate relationship had been with his wife. They married shortly after they met and the marriage was turbulent from the start, with heated arguments and physical abuse.
His only previous episode of mental illness was when he was aged 19 and suffered an episode of depression with psychotic features. This episode was brief and thought to be related to cannabis use.

Around the time he left school he began regular cannabis use and, following his first episode of mental illness, he began to misuse alcohol. When he was made redundant, about 6 months before the index offence, his drinking increased and he began to accuse his wife of seeing other men. About a month before the index offence his wife began to tell him that she was going to leave him.

He stabbed his wife to death after she returned from a night out with friends and he then called emergency services.

Following admission, his mental health improved fairly quickly with medication, and his risk factors were considered to be relationship difficulties, substance misuse, major mental illness and susceptibility to stress. He remained rather solitary and aloof and did not appear to have any real understanding of his problems. He has taken to periodically asking to leave hospital as he considers that everything is now 'sorted' and he does not require any further help. He has also started to mention the name of a young woman whom he had known when he was working and his hope is to make contact with her through social media. He has no unescorted off-ward time and has been reluctant to undertake psychological therapies.

\section{Formulation}

The matters to be decided are the details of the next stage of this man's treatment. He has been convicted of a serious violent offence committed when he was depressed, paranoid and misusing substances, but even though his health has improved he has developed little insight and could not, at least at this point, be relied on to self-manage if he were in conditions of greater freedom.

He experienced early parental separation and it is probable that subclinical depression and low selfesteem led to self-medication with substances, but he did appear to gain some satisfaction from his work in IT. His marriage was never particularly stable and the loss of his job and the prospect of losing his wife probably precipitated a deterioration in his mental state, an increase in his substance misuse and the fatal attack on her. It is possible that suicide as well as homicide might have been in his mind at that time.

At the time of his admission to hospital 4 years ago, his particular primary risk factors were considered to be relationship difficulties, major mental illness and susceptibility to stress. When these factors are more prominent he becomes much more liable to display poor problem-solving, with the use of violence, variable adherence to treatment and compliance with supervision, and poor insight. His personality structure and functioning were not assessed when he was admitted because of his poor mental state and have not as yet been fully assessed.

Although he has improved since admission, problems continue, as manifest by his lack of insight, his isolation and his rigidity. It remains uncertain to what extent these features are due to continuing low-grade illness and to what extent they are due to personality pathology. Assessment of the latter is complicated by a lack of collateral informants. 
The clinical team cannot be confident that he would adhere to treatment or engage if he were to be discharged from hospital at the present time, and the next stage of his treatment will be to maintain his stable mental state, try to gain greater understanding of his personality and consider whether any specific psychological interventions might be of assistance to him. Also it is necessary to monitor his relationships with those outwith hospital, including with the young woman whom he hopes to contact. There are therapeutic opportunities from this aspect of his case, but careful management will be important. It has been decided not to prevent any relationship developing, but this stance may have to be reviewed and any contact which he can make will be monitored carefully. Disclosure issues will also arise. During the next stage of his care some consideration will have to be given to the extent to which he is capable of change in order that unrealistic demands and expectations are not imposed. In addition, and because of his history of affective disorder, there remains the potential for self-harm and suicide attempts. Despite his wish to progress, the risk of absconding is considered to be too great for him to have unescorted off-ward time. The greatest concern is disengagement, a return to substance misuse and deterioration of his mental state, with further violence becoming a particular concern mainly in the context of further relationships or perhaps even friendships with either sex.

On the basis of all of the above, for the next stage of his treatment we will not yet permit unescorted off-ward time, we will encourage more group rather than solitary activities within the ward but still allow some of the latter, we will undertake a full assessment of his personality functioning and attitudes to women within intimate relationships, leading on to work on healthy relationships, we will monitor very closely his approaches to the former colleague and will regularly assess his mood. While this is ongoing, we will not arrange any further specific psychological therapies but will return to this at a later stage. Based on our knowledge of him, we believe that this will manage the level of risk that he poses to himself and to others.

This plan was discussed with him but he rejected it, stating that these were the opinions and decisions of others and there was nothing that he could do about it. Helping him to feel at least a degree of ownership of his care plan is another element of the next stage of his management.

Prepared by Dr C.D., consultant clinical forensic psychologist, during the clinical team meeting on 1 January 2016.

\section{Key aspects of the clinical formulation of this case}

- Despite continuous in-patient care for the past 4 years, there is clear acknowledgement of what remains unknown or poorly understood.

- The principle is to restrict the man's freedom and autonomy only to the extent that this is deemed necessary for his safety and the safety of others.

- Efforts will continue to help him to engage with his treatment and care plan, despite his firm opposition to doing so.
- This formulation includes elements of risk formulation.

\section{What does the formulation add?}

The analysis of the man's problems and the setting out of their origins, together with the recognition that his personality functioning remains poorly understood, would have been less likely to emerge from a more medically focused diagnosis and summary and it will provide a basis for psychological therapies in the time to come. Also, his response to attempts to engage him in his care plan will provide a benchmark of his insight against which future progress or the lack of it can be assessed. Some degree of insight will be necessary for him if he is to become capable of self-management.

\section{Case three: depression in a woman with intellectual disability}

\section{Summary}

A 40-year-old woman attended the learning disability psychiatry out-patient clinic. She has a mild learning [intellectual] disability secondary to Down syndrome. She was referred to the clinic by her general practitioner (GP), having been brought to the surgery by her sister, who was very concerned about her mental health. She was described as low, tearful, not attending to her personal care as well as she had done in the past and not interested in any of her previously enjoyed activities. The GP referred her to the clinic as he was concerned that she had become depressed and he sought advice regarding further management.

She generally keeps good health and has hypothyroidism which is well controlled with replacement therapy. Shortly after her father's death around 10 years ago, she developed a depressive episode which responded to antidepressant medication (fluoxetine), which she took for about 2 years before discontinuing as she had completely recovered from the episode.

She had been slow to achieve her developmental milestones and had been educated in the special educational needs system. She left school at the age of 15 . She was supported at home by her parents for several years before starting a placement at a local day centre 5 days a week, which she attended for many years and thoroughly enjoyed, establishing good relationships with staff members and other service users.

She had a happy childhood within a close family. She is the youngest child of six and throughout her childhood and adolescence, she maintained regular contact with her older siblings, who had left home. She developed a number of hobbies and interests, including knitting, painting and listening to music.

She lived in the family home with her parents, although was fairly independent. For example, she could travel by herself to familiar places and attend to her own personal care. After her father's death, she continued to live in the family home with her mother, until 5 years ago when her mother developed dementia and moved into a nursing home. At this 
point, she moved to her own tenancy near to her oldest sister. She kept in contact with her mother, visiting her at the nursing home on Saturdays.

She continued to attend her day centre 5 days a week. Unfortunately, around 1 year ago, there were significant changes at the day centre. Many of the staff who had worked there for years and knew her well retired or moved to other jobs. Some of the activities that she previously participated in were no longer offered. She no longer enjoyed the day centre and so made the decision to stop attending.

Since leaving the day centre, she has not participated in any other structured day-time activities. She began to spend increasing amounts of time at her sister's house and eventually gave up her tenancy to live with her sister on a full-time basis. She continued to visit her mother, until the mother's death around 4 months ago following a short illness.

She attended the psychiatry clinic appointment with her sister. Her sister described her as experiencing a range of symptoms consistent with a severe depressive illness which have worsened over the preceding 3 months. The sister described her as someone previously meticulous with personal hygiene who now needs significant prompting with this. She spends hours sitting unoccupied and just staring ahead, where previously she would be busy knitting or watching her favourite soaps on television. Her appetite is poor, with associated weight loss, and her sleep pattern is disturbed. Her sister admitted that she herself is struggling to come to terms with the loss of their mother and has not felt able to speak to anyone, even her sister, the patient, about their loss.

Clinically, the woman was dishevelled in her appearance, was objectively depressed in mood with very little reactivity of affect. She struggled to engage in the interview, sitting passively, offering little spontaneous speech. Although she seemed quite hopeless about the future, she denied any suicidal ideation.

\section{Formulation}

This is a 40-year-old woman with a mild learning disability secondary to Down syndrome. She was referred to the learning disability psychiatry outpatient clinic for assessment of her mental health. She presents with a 3-month history of worsening symptoms which are consistent with a severe depressive episode. Decisions are to be taken about the next stage of her care and treatment.

Her history of a previous depressive episode places her at greater risk of a recurrence of depression. She has had significant losses in the past year, which are likely to be contributory to her current presentation. She lost her day centre placement and, along with this, many positive relationships that she had built up over a number of years. She has lost her independence, giving up her own flat to live with her sister. Most recently, she has lost her mother, with whom she had a close relationship.

Since leaving her day centre, she has not replaced this with any other activities outwith the home. This lack of structure and routine to her day is likely to be maintaining her low mood. Her sister is currently also grieving the loss of their mother and has admitted that she feels unable at present to discuss what happened to her mother with the patient. It is uncertain how much the patient understands about the death of her mother. Her learning disability may affect her ability to understand death and the grieving process, and confusion over the loss of her mother might be perpetuating her depressed mood.

At present, her sister is happy to continue to support her in her home. She recognises that she is still managing her own feelings of loss in relation to her mother's death, but she retired some months ago and so feels she has time to look after her and wants to do so. This arrangement is contingent on the sister's capacity to continue to provide care, but it does seem to be appropriate as it would be best if the patient could be maintained in an environment familiar to her. Should her mental health deteriorate such that her sister is unable to provide the level of support required to keep her safe and maintain her welfare, then consideration could be given to hospital admission for intensive observation and treatment.

In terms of medication she will commence an antidepressant. Given her previous good response to fluoxetine this is recommended again at an initial dose of $20 \mathrm{mg}$ daily.

She will be referred to the community learning disability nursing service in order for nursing input to monitor her mood and response to the medication and, when she is able, to do some work with her concerning grief and loss. The plan is for weekly visits in the first instance. The particular concern is that, without adequate care and treatment, her mental health will deteriorate further, with even greater levels of self-neglect, and her predicament may lead to additional problems for the sister with whom she is living and who has problems of her own at the present time.

The patient will be seen again at the out-patient clinic.

This formulation was discussed with the patient and her sister. They were content with the factual content and were glad about the assistance which was proposed.

Prepared by Dr E.F., consultant psychiatrist, on 1 January 2016, following a telephone discussion with the GP and with a community learning disability nurse.

\section{Key aspects of the clinical formulation of this case}

- The patient's mental health problems are conceptualised in the context of her life, and her treatment includes consideration of what can be altered within her circumstances.

- Posing the question "why has the patient become ill now?' provides a way into this wider view of her care.

- The clinical formulation includes a social formulation.

\section{What does the formulation add?}

A simple case summary would deal predominantly with the patient's depressive illness. The preparation of the formulation, however, brings out the precipitating factors of her illness and identifies wider social factors that are likely to be protective for her in the future as she recovers. Also, regular discussion with the sister will ensure 
MCQ answers

$\begin{array}{lllll}1 b & 2 d & 3 \text { e } & 4 a & 5 d\end{array}$ that her own welfare, which will also be important for the patient's recovery, is not overlooked. Indeed, the carer herself could require referral to services if her circumstances became problematic.

\section{Summary}

These three cases illustrate the nature of formulation, the increased understanding of a case that will follow and the potential to reduce as much as possible the risk that aspects of a problem are overlooked and, by setting out the reasons for decisions, the danger that clinical decisions will be biased or overly subjective.

\section{Conclusions and the way ahead}

We have described in this article how formulation has progressed from being a relatively solitary task undertaken by a single senior clinician to a multidisciplinary exercise undertaken within the setting of a clinical team and with all team members contributing. Alongside this there has been a realisation that patients and their carers should also be actively involved in the process, present during the clinical team's discussions, afforded every opportunity to contribute and express their views, and helped whenever possible to feel some ownership of the final plans that emerge for the next stage of their care and treatment.

During the course of writing, however, we have observed the similarities between these developments in formulation and the developments that have taken place in clinical training and teaching (Hodges 2013). In this area too, the gaining of clinical knowledge is much less a solitary activity for libraries and the exam hall and more and more has included working in small groups, tutorials, role-play and regular feedback. We believe that the similarities between these parallel developments are not coincidence. In formulation the underlying task is to share and pool information, test assumptions, explore apparent contradictions, try to fill in gaps and develop a management plan which is based on as comprehensive information as can be gathered. In clinical teaching the objectives are the same. Information is gathered, shared and challenged in the hope that everyone's knowledge will be as soundly based and as balanced as possible. We have looked for, but not found, references making this link between the two processes, but nevertheless, we cannot but conclude that the parallel developments have taken place at the same time, for the same reasons and with the same objectives. The incorporation of the patient into the formulation process is entirely consistent with the fact that the patient is now considered to be part of their own management team.
These observations confirm that formulation and the principles that underpin it are a core aspect of modern clinical practice, but nothing stands still and it is likely that within a couple of decades or so the principles of formulation will have passed through further developmental stages. The truth is, of course, that nobody knows what lies ahead, but if we take a wild fanciful leap, maybe before too long genetic analysis will be a core part of a patient's clinical formulation. If that is what science allows us, then genetics may inform what will be the most appropriate stratified medical treatment, it may inform prognosis and perhaps even define what is needed by way of genetic re-sequencing. If so, what will be left for clinicians? But can a time ever come when there will not also be a place for psychological exploration and analysis and the insights and interventions that follow from this approach?

If the time were to come when there was no need for human psychology in formulation - nature without nurture - then humanity itself would be unrecognisable from what we understand it to be. This is not pleasant to contemplate. But there is one absolute certainty - clinical formulation will change and develop further in the time to come.

\section{References}

Badenoch J (2016) A doctor's duty of disclosure and the decline of 'The Bolam Test': a dramatic change in the law on patient consent. MedicoLegal Journal, 84: 5-17.

Eells TD, Lombart KG (2011) Theoretical and evidence-based approaches to case formulation. In Forensic Case Formulation leds P Sturmey, M McMurran): 3-32. John Wiley \& Sons.

Forrest A (1973) Companion to Psychiatric Studies. Churchill Livingstone.

Gelder M, Gath D, Mayou R (1994) The Concise Oxford Textbook of Psychiatry. Oxford University Press.

General Medical Council (2013) Establish and maintain partnerships with patients. In Good Medical Practice. GMC (http://www.gmc-uk.org/ guidance/good_medical_practice/partnerships.asp).

Hodges BD, Lingard L (2013) The Question of Competence: Reconsidering Medical Education in the Twenty-First Century. Cornell University Press.

Hollyman JA, Hemsi L (1983a) What do psychiatrists understand by formulation? Psychiatric Bulletin, 7: 140-3.

Hollyman JA, Hemsi L (1983b) What do examiners understand by formulation? Psychiatric Bulletin, 7: 165-7.

Mohtashemi R, Stevens J, Jackson PG, et al (2016) Psychiatrists' understanding and use of psychological formulation: a qualitative exploration. BJPsych Bulletin, 40: 212-6.

Montgomery v Lanarkshire Health Board [2015] UKSC 11.

Persons JB (2008) The Case Formulation Approach to Cognitive-Behavior Therapy. Guilford Press.

Royal Australian and New Zealand College of Psychiatrists (2014) RANZCP Clinical Examinations: Formulation Guidelines for Trainees (Formulation Guidelines 0304). RANZCP (http://www.psychtraining.org/ RANZCP-Formulations-Guide.pdf). 
Royal College of Psychiatrists (2010) A Competency Based Curriculum for Specialist Training in Psychiatry: Specialists in General Psychiatry. Royal College of Psychiatrists (http://www.rcpsych.ac.uk/pdf/General\%20 Psychiatry\%20submission\%200ctober\%202010_Mar15Update1.pdf).

Royal College of Psychiatrists (2013) A Competency Based Curriculum for Specialist Core Training in Psychiatry: Core Training in Psychiatry CT1-CT3. Royal College of Psychiatrists (http://www.rcpsych.ac.uk/pdf/ Core\%20Curriculum_FINAL\%20Version_July2013 updatedJun15.pdf).
Royal College of Psychiatrists (2017) Using Formulation in General Psychiatric Care: Good Practice (Occasional Paper OP103). Royal College of Psychiatrists.

Slater E, Roth M (1977) Clinical Psychiatry (3rd edn). Baillière, Tindall $\&$ Cassell.

Tarrier N, Calam R (2002) New developments in cognitive-behavioural case formulation, epidemiological, systemic and social context: an integrative approach. Behavioural and Cognitive Psychotherapy, 30: 311-28.

\section{MCOs}

Select the single best option for each question stem

1 During the preparation of a formulation there should, if possible, be discussion with all of the following except:

a the patient

b the service manager

c the main carer

$d$ the ward manager

e the key worker.

2 Formulation is intended to increase the likelihood of all of the following except:

a important aspects of the case are not overlooked

b the patient's perspective and wishes are known and taken into account in the preparation of the care plan

$c$ the perspective and wishes of the carer are known and taken into account in the preparation of the care plan d decreasing the risks of litigation should something go wrong

e the case can be transferred between services without important details being lost.

\section{Clinical formulation shares many of its} core principles with:

a psychoanalysis

b developments in modern NHS management

c developments in medical science

$\mathrm{d}$ developments in public/private funding

e developments in clinical education and training.

4 Which of the following should be obtained/ undertaken wherever possible before formulation is completed?

a As full a history as possible, taken from the patient, using an independent interpreter if necessary

b Background information from informants if available c Background information from health records if available

d Background information from social services if available

e Information regarding any previous convictions if available.

5 Formulation is:

a another term for a case summary

b a type of risk assessment

c a process that will give protection to a clinical team if something goes wrong

d structured in order to support both multidisciplinary teams and patients towards the most suitable and effective interventions

e important in the modern NHS because it allows the costs of treatment to be calculated and budgeted more accurately. 